\title{
SYNTHESIS OF ALUMINA NANOPOWDER USING MIXED FUEL BY SOLUTION COMBUSTION APPROACH
}

\author{
Ch. Naga Siva Krishna ${ }^{1}$, Mangam Venu ${ }^{2}$ \\ ${ }^{1,2}$ Department of Mechanical Engineering, Vishnu Institute of Technology, Bhimavaram, Andhra Pradesh, India- 534 \\ 202. \\ sivakrish307@gmail.com
}

\begin{abstract}
The combustion synthesis is a technique using Glycine and urea as fuels and aluminium nitrate as an oxidizer to produce alumina nano powder. The combustion reaction shows the variation of gases produced and combustion temperature with variation in fuel to oxidizer ratio. Amorphous structure is observed for as-synthesized powder using glycine alone. Crystallinity can be obtained by further calcination at desired temperature. Crystalline alumina powder can be obtained by using urea as a fuel. By using the mixed fuel (Glycine+Urea), there will be sufficient energy for combustion and good crystalline alumina powder can be obtained. The obtained alumina powder is free from organic residues. X-ray diffraction shows the formation of pure alumina powder. SEM (Scanning Electron Microscope) studies show the morphology of the powder.
\end{abstract}

Keywords: Alumina, Scanning Electron Microscope, Combustion Synthesis $* * *$

\section{INTRODUCTION}

Alumina $\left(\mathrm{Al}_{2} \mathrm{O}_{3}\right)$ powders in nano size find a wide variety of applications for advanced engineering materials today. The development of alumina nano powders has been increased in the recent years. They have high potential for use as coatings[1,2],solid state fabrication of YAG(yttrium aluminium garnet)[3], nanocomposite for structural applications [4,5], high density ceramics[6], sintering aid for ceramics [7],etc.

Solution combustion synthesis is an effective method for producing nano-sized powders[8-10]. The process is based on redox reactions between metal salts and reducing agents such as glycine or urea.

One of the cheapest reducing agent is glycine. It contains carboxylic group at one end and an amino group at the other end, which results in the formation of zwitter ions on dissolving in water with both positive and negative charges. This zwitterionic character of glycine helps to complex metalions of varying sizes to maintain compositional homogeneity among the constituents. Another cheapest reducing agent is urea[11-13].

The initial composition of the solution containing aluminium nitrate, glycine and urea was calculated from the oxidizing and reducing valencies of the oxidizer and fuel using propellant chemistry. The oxidizing-reducing valencies for aluminium nitrate, glycine and urea is $-15,+9$ and +6 . The molar proportion for aluminium nitrate with glycine and urea are $1: 1.67$ and $1: 2.5[12,13]$.

\section{EXPERIMENTAL PROCEDURE}

Aluminium nitrate $\left[\mathrm{Al}\left(\mathrm{NO}_{3}\right)_{3} .9 \mathrm{H}_{2} \mathrm{O}\right]$, glycine $\left[\mathrm{C}_{2} \mathrm{H}_{5} \mathrm{NO}_{2}\right]$ and urea $\left[\mathrm{CO}\left(\mathrm{NH}_{2}\right)_{2}\right]$ with $98.5 \%, 99.5 \%$ and $99.5 \%$ purity, respectively were used for synthesis of alumina nano powder. It was synthesized by using three different modes as shown in Fig-1.

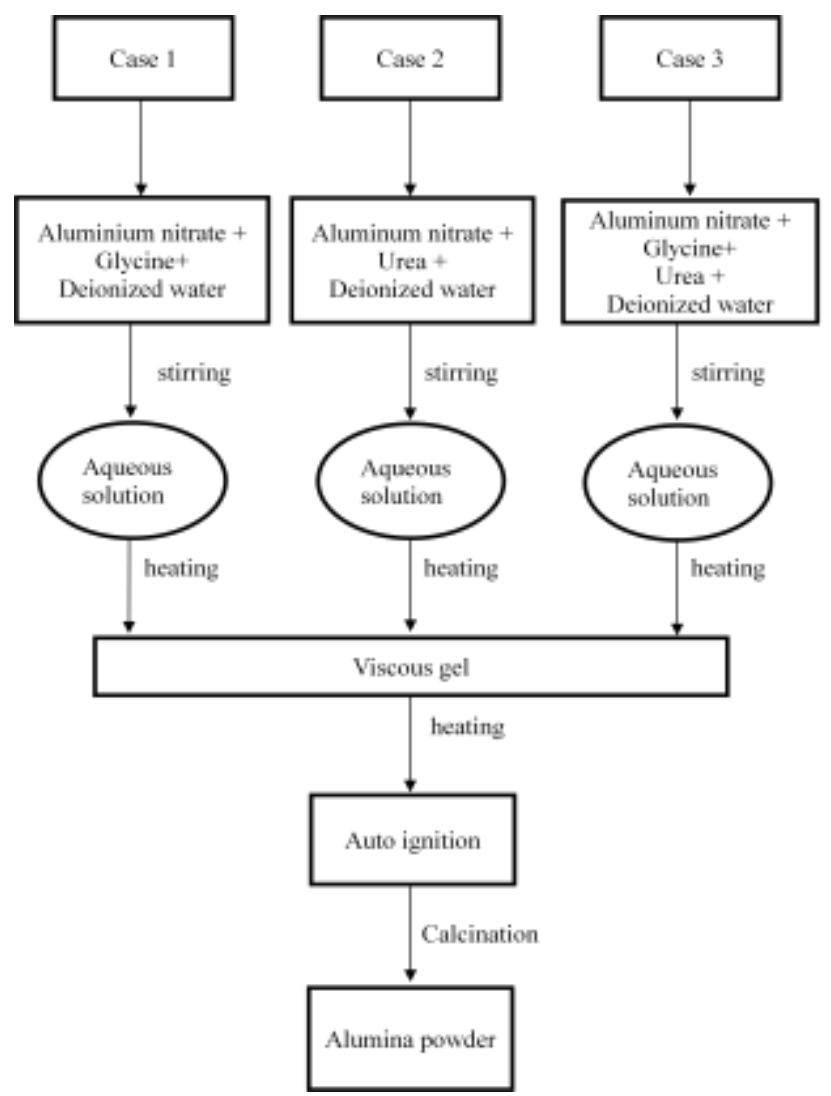

Fig-1:Schematic representation of synthesis of alumina. 
Case-1 (Glycine is the only fuel)

Initially aluminium nitrate and glycinewere taken in the stoichiometric ratio. The chemicals were weighed according to the ratios and mixed in the deionized water. The solution was then continuously stirred at $300 \mathrm{rpm}$ for two hours with the aid of magnetic stirrer. Then the solution was heated using heater. The same process followed for fuel richandlean mixtures.

Case-2 (Urea is only the fuel)

In this case, aluminium nitrate used as an oxidizer and urea is taken as the single fuel. The powders are produced in stoichiometric ratio, fuel rich and fuel lean using urea as the fuel.

\section{Case-3 (Mixed fuel)}

Aluminium nitrate, glycine and urea were mixed in the varying proportions of glycine and urea. Initially glycine content was more and urea was less, later the proportions are vice-versa.

Table-1: Proportions of glycine and urea.

\begin{tabular}{|l|l|l|}
\hline $\begin{array}{l}\text { Aluminium } \\
\text { Nitrate } \\
\text { (Grams) }\end{array}$ & $\begin{array}{l}\text { Glycine } \\
\text { (Grams) }\end{array}$ & $\begin{array}{l}\text { Urea } \\
\text { (Grams) }\end{array}$ \\
\hline 36.79 & 10.29 & 2 \\
\hline 36.79 & 8.29 & 4 \\
\hline 36.79 & 6.29 & 6 \\
\hline 36.79 & 4.29 & 8 \\
\hline 36.79 & 2.29 & 10 \\
\hline
\end{tabular}

The chemicals were mixed in the proportion as shown in the table-1.During the heating process water gets evaporated, a gel is formed. After the formation of gel, during heating auto ignition takes place and the product is formed like a foam or sponge structure. The product obtained is kept in a mortar and grinded into powder with the aid of pestle. The powders obtained by using glycine, urea and mixed fuel are calcined in a muffle furnace at temperatures $9500^{\circ} \mathrm{C}, 750^{\circ} \mathrm{C}$ and $850^{\circ} \mathrm{C}$ respectively. The calcination process was done to remove the unburnt chemical species if any present due to incomplete combustion.

The calcined powders were then characterized using XRD and SEM. The X-ray Diffraction patterns of the prepared powders were recorded and were compared with the powders with different modes. The morphology of the powders was studied using scanning electron microscope.

\section{CHEMICAL EQUATIONS}

Case-1

Equation-1(Stoichiometric ratio)

$2 \mathrm{Al}\left(\mathrm{NO}_{3}\right)_{3}+3.34 \mathrm{C}_{2} \mathrm{H}_{5} \mathrm{NO}_{2} \longrightarrow \mathrm{Al}_{2} \mathrm{O}_{3}+6.68 \mathrm{CO}_{2}+$ $4.67 \mathrm{~N}_{2}+8.35 \mathrm{H}_{2} \mathrm{O}$

Equation-2(fuel increased by 20\%)
$2 \mathrm{Al}\left(\mathrm{NO}_{3}\right)_{3}+4 \mathrm{C}_{2} \mathrm{H}_{5} \mathrm{NO}_{2}+1.5 \mathrm{O}_{2} \rightarrow$

$\mathrm{Al}_{2} \mathrm{O}_{3}+8 \mathrm{CO}_{2}$ $+5 \mathrm{~N}_{2}+10 \mathrm{H}_{2} \mathrm{O}$

Equation-3 (fuel decreased by 20\%)

$\overrightarrow{2 \mathrm{Al}\left(\mathrm{NO}_{3}\right)_{3}}+2.67 \mathrm{C}_{2} \mathrm{H}_{5} \mathrm{NO}_{2} \longrightarrow$

$4.33 \mathrm{~N}_{2}+6.67 \mathrm{H}_{2} \mathrm{O}+1.5 \mathrm{O}_{2}$

$\mathrm{Al}_{2} \mathrm{O}_{3}+5.34 \mathrm{CO}_{2}+$

Case-2

Equation-1 (Stoichiometric ratio)

$2 \mathrm{Al}\left(\mathrm{NO}_{3}\right)_{3}+5 \mathrm{CO}\left(\mathrm{NH}_{2}\right) \longrightarrow \mathrm{Al}_{2} \mathrm{O}_{3}+5 \mathrm{CO}_{2}+8 \mathrm{~N}_{2}+$ $10 \mathrm{H}_{2} \mathrm{O}$

Equation-2 (fuel increased by 20\%)

$2 \mathrm{Al}\left(\mathrm{NO}_{3}\right)_{3}+6 \mathrm{CO}\left(\mathrm{NH}_{2}\right)_{2}+1.5 \mathrm{O}_{2} \longrightarrow$ $+9 \mathrm{~N}_{2}+12 \mathrm{H}_{2} \mathrm{O}$

$\mathrm{Al}_{2} \mathrm{O}_{3}+6 \mathrm{CO}_{2}$

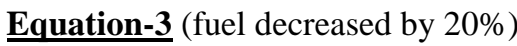

$\overrightarrow{2 \mathrm{Al}\left(\mathrm{NO}_{3}\right)_{3}}+4 \mathrm{CO}\left(\mathrm{NH}_{2}\right) \longrightarrow \mathrm{Al}_{2} \mathrm{O}_{3}+6 \mathrm{CO}_{2}+9 \mathrm{~N}_{2}+$ $12 \mathrm{H}_{2} \mathrm{O}+1.5 \mathrm{O}_{2}$

\section{RESULTS AND DISCUSSION}

The powders obtained before calcination with glycine for stoichiometric, fuel rich, fuel lean ratios are in grey, dark grey and light grey in colour and aftercalcination their colour changed to pure white. The powders with urea are initially lightwhite in colour and after calcination they changed to pure white. The powders obtained using mixed fuel are initially grey colour with glycine rich(urea lean) and gradually changed to white colour for glycine lean(urea rich). After calcination the powders changed from grey colour to light cement colour. This change in colour of the powders is due to the variations in the fuel ratios.

The SEM morphology of the powders is shown in Fig-2. The formation of foamy agglomerated particles with the presence of voids with glycine alone as fuel is shown in Fig2(a). The agglomerates of $\mathrm{Al}_{2} \mathrm{O}_{3}$ particles obtained with urea are denser, large, voids are not presentas shown in Fig-2(b). The formation of voids on the particles attribute to the evolution of a larger amount of gas during combustion process.

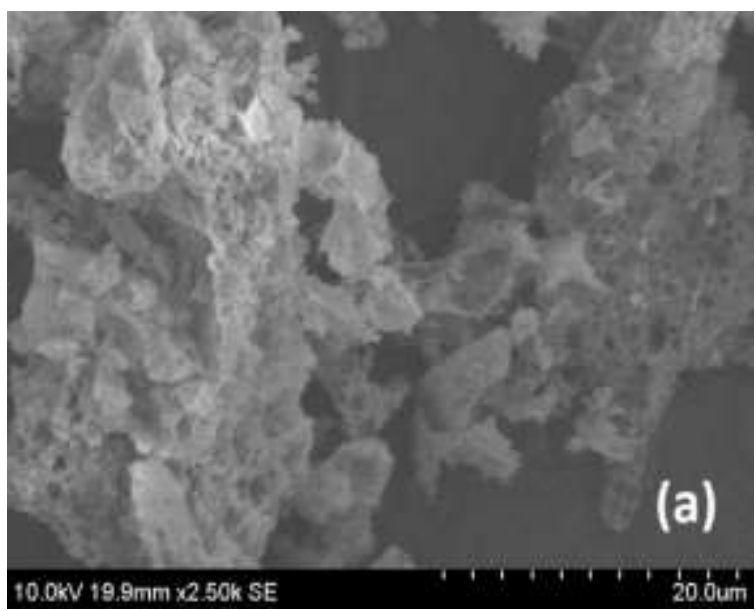




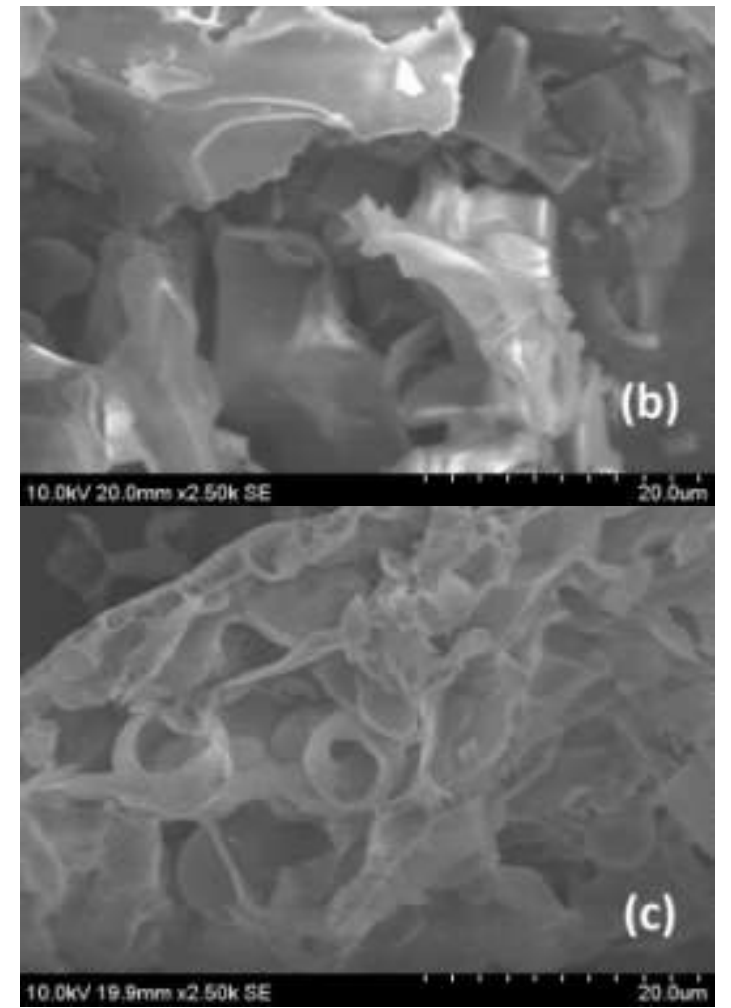

Fig-2:SEM morphology of aluminium oxide obtained with(a)glycine, (b)urea and (c)mixed fuel.

In the mixed fuel, SEM image in Fg-2 (c) shows the presence of voids in the agglomerate particles due to the presence of glycine. With the decrease in the proportion of glycine, the voids were decreased; denser and larger particles were obtained.XRD results show the formation of amorphous alumina for powders using glycine as fuel. XRD plots confirm the complete formation of single phase $\alpha$ $\mathrm{Al}_{2} \mathrm{O}_{3}$ in both the cases using urea and mixed fuels.

\section{CONCLUSION}

Solution combustion synthesis is an easy, efficient technique for the synthesis of pure alumina. The fuel used, oxidantfuel ratio plays a major role on the powder properties. Glycine alone does not act as a good fuel, as it evolved more amount of gases during combustion. The generated temperature was not sufficient for complete combustion leading to formation of amorphous alumina. In case of urea and mixed fuel (glycine + urea), the generated temperature was sufficient for complete combustion which leads to the formation of pure alumina.

\section{REFERENCES}

[1]. J.C.Toniolo, M.D. Lima, A.S. Takimi, C.P. Bergmann, Synthesis of alumina powders by the glycine-nitrate combustion process, Materi- als Research Bulletin (2005) 561-571 40.

[2]. Venu Mangam, Karabi Das, Siddhartha Das, Structure and properties of electrocodeposited $\mathrm{Cu}-$ $\mathrm{CeO}_{2}$ nanocomposite thin films, Materials Chemistry and Physics 120 (2010) 631-635.
[3]. Kiranmala Laishram , Rekha Mann, Neelam Malhan,Single step synthesis of yttrium aluminum garnet $\left(\mathrm{Y}_{3} \mathrm{Al}_{5} \mathrm{O}_{12}\right)$ nanopowders by mixed fuel solution combustion approach,Ceramics International 37 (2011) 3743-3746.

[4]. H. Nasiri, J. Vahdati Khaki, S.M. Zebarjad, One-step fabrication of $\mathrm{Cu}-\mathrm{Al}_{2} \mathrm{O}_{3}$ nanocomposite via solution combustion synthesis route, Journal of Alloys and Compounds 509 (2011) 5305-5308.

[5]. J. Kishan, Venu Mangam, B.S.B. Reddy, Siddhartha Das, Karabi Das,Aqueous combustion synthesis and characterization of zirconia-alumina nanocomposites, Journal of Alloys and Compounds 490 (2010) 631-636.

[6]. V.D. Zhuravlev, V.G. Vasil'ev, E.V. Vladimirova, V.G. Shevchenko, I.G. Grigorov, V.G. Bamburov, A.R. Beketov, M.V. Baranov, Glycine-nitrate combustion synthesis of finely dispersed alumina, Glass Physics and Chemistry 36 (4) (2010) 506-512.

[7]. M.A. Rodri'guez , C.L. Aguilar, M.A. Aghayan,Solution combustion synthesis and sintering behavior of $\mathrm{CaAl}_{2} \mathrm{O}_{4}$, Ceramics International 38 (2012) 395-399.

[8]. T. Mimani, K.C. Patil, Solution combustion synthesis of nanoscale oxides and composites, Materials Physics and Mechanics 4 (2001) 134-137.

[9]. Kiranmala Laishram , Rekha Mann, Neelam Malhan,A novel microwave combustion approach for single step synthesis of $\alpha-\mathrm{Al}_{2} \mathrm{O}_{3}$ nanopowders, Ceramics International $38 \quad$ (2012) 1703-1706.

[10]. Alexander S. Mukasyan, Paul Epstein, Peter Dinka, Solution combustion synthesis of nanomaterials, Proceedings of the Combustion Institute 31 (2007) 1789-1795.

[11]. Haribabu Palneedi, Venu Mangam, Siddhartha Das, Karabi Das, Effect of fuel-to-nitrate ratio on the powder characteristics of nanosized $\mathrm{CeO}_{2}$ synthesized by mixed fuel combustion method,Journal of Alloys and Compounds 509 (2011) 9912- 9918.

[12]. Amit Sharma, O. P. Modi and Gaurav K Gupta, Effect of fuel to oxidizer ratio on synthesis of Alumina powder using SolutionCombustion Technique-Aluminium Nitrate \& Glycine combination, Advances in Applied Science Research, 2012, 3 (4)2151-2158.

[13]. Amit Sharma, O. P. Modi and Gourav K Gupta, Combustion Synthesis of Nanocrystalline $\mathrm{Al}_{2} \mathrm{O}_{3}$ Powder using Aluminium Nitrate and Urea as reactants-influence of reactant composition, Advances in Applied Science Research, 2012, 3 (6)3819-3824. 